und Karrierewege der betreffenden Personen. So deckt Furch Personalverflechtungen, Kapitalbeteiligungen und Shareholder Agreements zwischen den untersuchten Unternehmen in beiden Ländern auf.

Absolut lesenswert - gerade auch angesichts der gegenwärtigen Situation - sind seine Darstellungen zur historischen Entwicklung der Finanzsysteme beider Länder. Für die Bundesrepublik werden so zum Beispiel die umfangreichen Unternehmensverflechtungen in der so genannten „Deutschland AG“ aufgezeigt, die bis in die 1990er Jahre existierte und in der die Deutsche Bank seit jeher eine exponierte Rolle einnahm. Furch analysiert zudem, welchen Beitrag die EU zur Liberalisierung der Finanzmärkte geleistet hat und wie sich einzelne Aspekte der Corporate Governance Modelle in beiden Ländern gewandelt haben. Im Ergebnis könne jedoch kein radikaler Wandel konstatiert werden, da sich sowohl die Bundesrepublik als auch Italien „weiterhin stark von liberalen Outsider-Systemen“ (S. 237) unterscheiden. Dass sich Italien - trotz diverser rechtlicher Anpassungsmaßnahmen in den letzten Jahren - durch eine „starke institutionelle Stabilität“ (S. 238) auszeichnet, erklärt auch die Performanz des Landes in der Finanz- und Wirtschaftskrise.

Hanna Lierse analysiert in ihrer historisch-vergleichenden Dissertation die Währungsund Unternehmenssteuerpolitik der EU. Um die Herausbildung spezifischer Governanceformen in beiden Policyfeldern aufzuzeigen, fragt sie nach dem Einfluss politischer Ideen und Diskursverläufe auf die Entscheidungsfindung - ein Forschungsdesiderat auch hinsichtlich der neuen Verflechtungen zwischen Economic und Fiscal Governance. Lierses Diskursanalyse besteht aus einer Auswertung einschlägiger deutscher und britischer Presseorgane. Chronologisch wird dabei der Einfluss zentraler (ökonomischer) Ideen und Argumente zu einzelnen Maßnahmen der EU in beiden Politikfeldern beleuchtet. Lierse kommt so zu dem Schluss, dass sich die Europäische Kommission in der Vergangenheit stets an vorherrschenden ökonomischen Positionen einflussreicher Politiker orientiert habe. Eine Gewähr für eine erfolgreiche Umsetzung entsprechender Reformen sei damit jedoch per se nicht verbunden gewesen. Mit Blick auf die Dominanz der austeritätspolitischen Maßnahmen zur Bekämpfung der gegenwärtigen Finanz- und Wirtschaftskrise, die ganz maßgeblich von der deutschen Bundesregierung forciert worden sind und die Finanzmarktakteure eher schonen, liefert Lierses Ansatz wertvolle Hinweise auch für das Verständnis des neuen Konnexes zwischen der inzwischen stark europäisierten Finanz- und Wirtschaftspolitik der Mitgliedstaaten.

Henrik Scheller

\title{
Finanzen als die „Nerven der Republik“ - ein Vergleich von sechs Föderalstaaten
}

Egner, Björn: Staatsausgaben in Gliedstaaten föderaler Systeme. Deutschland, Österreich, Schweiz, USA, Kanada und Australien im Vergleich (Reihe "Staatlichkeit und Governance in Transformation", Band 2), Nomos Verlagsgesellschaft, Baden Baden 2012, 302 Seiten, € 54,-.

Dass die Verhältnisse in föderalen Systemen immer auch eine finanzielle Seite haben, ist bekannt. Spätestens das Stichwort Länderfinanzausgleich, Chiffre für ein seit Gründung der Bundesrepublik nicht befriedigend gelöstes Dauerproblem des deutschen Föderalismus, erinnert beständig an den Spruch Bodins von den Finanzen als den Nerven der Republik. Mit 
den Problemen der Finanzbeziehungen von Gliedstaaten untereinander und im Verhältnis zum Bund befasst sich Björn Egner.

In seiner Darmstädter Habilitationsschrift zeigt er, dass Politikwissenschaft sehr viel mit Mathematik zu tun haben kann. Zwar dankt er im Vorwort einem seiner Lehrer, ihn vor zu einem starken Abdriften in die politische Ökonomie bewahrt zu haben, aber eine finanzwissenschaftliche Studie dürfte kaum weniger Formeln enthalten. Die Arbeit gliedert sich in insgesamt acht Kapitel. Nach einer kurzen Einleitung gibt es einige konzeptionelle Vorbemerkungen (Kapitel 2), in denen verdeutlicht wird, welche Forschungslücke Egner schließen will: bei der Erforschung von Staatstätigkeit besonders jene Teile in den Blick zu nehmen, die von Gliedstaaten mit eigener Staatsqualität entfaltet werden. Dabei geht es ihm erstens um die Bestimmung, ob Gliedstaaten in föderalen Systemen nach den Determinanten ihrer Ausgabenpolitik tatsächlich Staaten sind oder aber bloß nachgeordnete Verwaltungseinheiten. Zum zweiten will Egner (anhand der Untersuchung von bereits vorliegenden intra-nationalen Vergleichen) zur Beantwortung der Frage beitragen, „ob die für föderale Systeme typischen politischen Interaktionen eine gemeinsame Logik besitzen oder die bestehenden föderalen Systeme so verschieden sind, dass sich keine gemeinsame Logik identifizieren lässt".

Im dritten Kapitel gibt Egner einen Überblick über den Forschungsstand zum Thema Ausgabenpolitik (von Staaten insgesamt) und stellt 14 Hypothesen auf, die in 14 Variablen übersetzt werden, mit denen er am Schluss der Arbeit im Wege quantitativ-statistischer Vergleiche rechnen kann. In Kapitel 4 („Ausgabenpolitik in Gliedstaaten föderaler Systeme“) werden die Überlegungen von Kapitel 3 auf die im Titel der Arbeit genannten Föderalstaaten angewandt und die Hypothesen um weitere fünf ergänzt.

Nach einem Methodenkapitel wird zunächst eine vergleichende und sodann eine vertiefende Analyse des vorhandenen und aufbereiteten Datenmaterials vorgenommen. Nachdem im Laufe der Arbeit einzelne Hypothesen falsifiziert oder bestätigt wurden, präsentiert Egner im letzten Kapitel die Schlussfolgerungen: Zur ersten Fragestellung ist keine eindeutige Antwort möglich, weil sich die untersuchten Länder zu stark voneinander unterschieden. Ein aber doch deutlich herausgestelltes Teilergebnis ist, dass die Bundesländer Österreichs anhand des Maßstabs ihrer Ausgabenpolitik keine Staaten sind. Österreich müsse aus der Liste der Föderalstaaten gestrichen werden.

Die zweite Hauptfragestellung der Arbeit lässt sich naturgemäß nicht so eindeutig beantworten. Eines der Ergebnisse - im Grunde die für diese Arbeit finale Schlussfolgerung lautet, dass institutionelle Arrangements entscheidend für das Ausgabenverhalten in Föderalstaaten sind, dass Staatsausgaben immer mit der jeweiligen institutionellen Ordnung zusammenhängen. In dem in Föderalstaaten auf zwei Ebenen doppelt vorhandenen Institutionengeflecht zeigten politische Akteure ein Verhalten, das mit den traditionellen ökonomischen Modellen nur schwer erklärbar sei. Am Ende muss sich der Leser, der ansonsten selbst nicht so geübt ist in der Anwendung ökonomischer Formeln, hier von Egner bestätigt fühlen. Und sei es auch nur in der Detailfrage, wie Föderalstaaten mit dem Thema Bailout umzugehen pflegen. 